\title{
Performing Elusive Mobilities: Ritualization, Play, and the Drama of Scheduled Departures
}

\author{
Phillip Vannini, PhD \\ Associate Professor \\ School of Communication and Culture \\ 2005 Sooke Road \\ Royal Roads University \\ Victoria BC V9B 5Y2 \\ CANADA
}

Phone: (250) 391-2600 ext. 4477

Fax: (250) 391-2694

phillip.vannini@royalroads.ca

Drawing upon three years of ethnographic fieldwork conducted in ferry-dependent islands and remote coastal communities of British Columbia, this paper examines the process of catching a ferry in time for a scheduled sailing. Through performance, interactionist, and non-representational theory I argue that the weaving of a journey toward the ferry terminal can be a suspenseful drama, within which a scheduled departure works as a potential to be actualized through the performance of skillful acts of mobility. The affective, ritualistic, and playful components of passengers' journeys are examined through the lens of performance. Timing, spacing, and acting occasion differential ecologies of affect.

Keywords: Performance; affect; mobility; play; ritual; drama; suspense; rhythm.

Spatial mobility is not a fait accompli. To be on the move is to strive, to labor, to perform travail (Spinney, 2006). Lately, research on mundane spatial mobilities has begun to shed light on the taskscapes of transportation-mediated movement and the skills passengers practice in negotiating these environments (e.g. Bissell, 2009; Edensor, 2003; Holley, Jain, and Lyons, 2008; Jones, 2005; Laurier, 2004; Lofgren, 2008; Watts, 2008). These studies have clearly shown how mobilities are hard-wrought intersubjective accomplishments, but much less attention has been dedicated to how spatial mobility acts fail to achieve their aims and how social actors need to adjust or abort plans, 
settle for compromises, and try again later. This paper's objective is to correct this tendency and examine from a more-than-representational perspective (Lorimer, 2005) how mundane spatial mobilities are subject to happenstance, unpredictability, poor or careless planning, faulty execution, fate, and playfulness. ${ }^{1}$

Spatial mobility practices are very aleatory especially when we take into account "asignifying ruptures, breaks, [and] discontinuities" emerging from multimodal "connections" (Dewsbury, 2000, pages 476-477). Take routine daily travel for example. Going to work is hardly ever performed unimodally; we may walk to our car, drive to a park-and-ride lot, catch our bus, connect to another bus, then walk a bit more to the office. The more connections between various modes of transport the higher are the difficulties to endure, as the higher is the potential for things to "unfold otherwise" (Dewsbury et al, 2002). Little knowledge, however, exists on the multimodality of spatial mobilities in their everyday complexities and thus on how people "make detours" and "sketch out rises and falls" (Deleuze and Parnet, 2006, page 93). Researchers tend to focus on what happens whilst on trains or buses, for example, but neglect to examine how passengers get to, or fail to, get to their buses or trains in the first place. By focusing on the "intermezzo" (Dewsbury, 2000) process of "gathering" (Vannini, 2011a) practiced by people dependent on ferry boats-a much neglected means of transport by the mobilities literature-in this paper I aim to shed light on the elusive aspects of spatial mobilities.

A focus on the elusiveness of spatial mobilities, it is hoped, can shed light on several dimensions of movement under-examined within the mobilities literature. A focus on elusiveness can yield a better understanding of the individual experience of travel failure (e.g. missed connections due to being late), but also and more broadly of the socio-ecological organization relevance of the aleatory dimensions of movement. From the way airlines and airports coordinate connecting flights, to the systems in place to guarantee multimodal (e.g. train-bus) urban transit 
connections, it is evident how multiple social actors attempt to optimize control and predictability of travel and minimize risk of failure. Yet, chance refuses to be regimented. As I argue throughout this paper in large part this is because mobility is performative and any performance carries within the genes of its own success, as much as its own undoing.

Data for this article are drawn from a three year mobile ethnography (cf. Watts and Urry, 2008) conducted in three dozen island and remote coastal communities throughout the coast of British Columbia, Canada. Access to all these areas is provided by an extensive network of ferry boats owned and operated by BC Ferries. BC Ferries conducts operation in 47 ports of call through a multitude of routes ranging from 10 minutes to 36 hours in length. Because there are no bridges, these boats are seen as lifelines. Some people may travel as frequently as almost every day or as infrequently as once, twice, or half a dozen times a year. Regardless of personal travel frequency or purpose, conditions are very diverse across different ferry-dependent communities with regard to sailing frequency, duration, costs, and vessel size.

Participant observation entailed travel to, on, and from ferry boats, for a total of about 250 journeys over three years, and 400 qualitative interviews conducted with a diverse sample of island and coastal residents. Instead of a typical data display I offer fragmentary and narrative data montages which enact (Dewsbury et al, 2002; Wylie, 2005) the doings of elusive mobility performances as "active and affective interventions in a world of relations and movements" (McCormack, 2005, page 122). In order to capture some of the diversity of the process of catching a ferry, the montages portray different people, sites, and circumstances. Constructed as a collage through various bits of observations and interviews, these montages are not meant to represent ideal types, but rather to create impressions and evoke affect. The elusiveness of mobility-my data enactments and presentations show_occasions the emergence and diffusion of suspense: a form of affect to which I dedicate my attention in the concluding section. 


\section{Performing Spatial Mobilities}

Corporeal movement must be "performed." There are many different types of performance. Some performances are explicitly framed and presented as such, whereas others-mostly corresponding with everyday life ones-are looser, less structured. Mundane mobilities such as going to work (Blumen, 2007) typify the latter. They most closely resemble ritualistic types of performances in that they follow an order shaped by habit and routine. Their performativity comes from the creative practice of movement: an action quintessential to all forms of performance. More precisely, to move is to create presence across "timespaces" (May and Thrift, 2001). From a more-than-representational perspective to move is to perform since "performance deals with actions more than text: with habits of the body more than structures of symbols, with illocutionary rather than propositional force" (Schieffelin, 1998, page 194). Performance, after all, is twice-behaved behavior (Schechner, 2003): an ensemble of moves that people more or less reflexively practice, prepare, plan and adjust for in relation to specific circumstances, drawing upon bits of familiarity, cultural codes, and know-how.

Everyday life is rich with "forms of mobility that are enduring, predictable, habitual, repetitive" (Binnie et al, 2007, page 166). In spite of this mundane nature, everyday mobile rituals are creative practices demanding focus and skill (Watts, 2008). Even though they are permeated by relatively un-reflexive habits, as Edensor (2003) suggests, everyday mobility rituals allow for possibilities to transcend the banal, escape uniformity, and to engage in complex interactions that generate the distribution of affect, the building of shared habits, and the solution of common problems. The ritualization of mundane spatial mobilities therefore does not emerge from its expressive symbolic value, but rather its affective consequentiality. Performance, in this sense, resides in routines' capacity to affect outcomes, to play with possibilities, to bend and reshape the world, and to accomplish goals (Schieffelin, 1998). Just like a sports car performs well by moving fast and keeping on the road, a commuter performs well by getting there on time, and perhaps even 
in style. The performance of spatial mobility can therefore be intended as a taskscape: "a pattern of activities 'collapsed' into an array of features" (Ingold, 2000, page 198) and emerging "as nodes in a matrix of movement” (page 219).

Like all performances, travel unfolds as the succession of three interrelated taskscapes: gathering, the playing out of an action for which people gathered, and dispersing (Schechner, 2003). In the context of coasters' and islanders' travel, gathering encompasses all the activities leading up to embarking. The end point of their gathering is a scheduled ferry departure: a ritual finality which solicits different rhythms of movement from would-be passengers coalescing together in a common timespace. A scheduled departure works in many ways. To begin with, it is a "connection" in both the everyday sense of the word, and in the theoretical sense intended by Dewsbury (2000, page 476) as an action facilitating, instigating, and linking with an assemblage of performances. Secondly, it is a “deferred affordance” (Bissell, 2009, page 178): a mere “ensemble of possibilities" (de Certeau, 2002, page 98) to be actualized, to be caught in other words, through successful movement. Thirdly, is an "irretrievable event" (Dewsbury, 2000) which both constrains and allows for the creativity of those who struggle to gather there in time. Fourthly, it is a key "moment" (cf. Lefebvre, 2004): a crucial chronologically-fixed transition which delineates an eventful time as a "shift from the possible to the real" (Dewsbury, 2000, page 479).

All of these characterizations point to a scheduled departure's quality of auspiciousness. Ritualization, writes Grimes (1995) occurs whenever people wish to concentrate on an event's auspiciousness, so as to consecrate it, master it, and in order to actualize the transition from "here" to "there" and thus to "heighten feelings and calm them in the same moment" (Grimes, 1995, page 71). Auspiciousness is impregnated with contingency. Any ritual argues Schieffelin (1998, page 197) "is inherently a contingent process." Contingency resides in whether the performance itself works (Schieffelin, 1998). Getting "there" in time involves "skilful interaction between [passengers] in 
accordance with the regulations and cultural norms of the road" (Edensor, 2003, page 155). Herein elusiveness emerges: at the very crossroad of ritualization and contingency, or auspiciousness and mundaneity, of skill and shortcoming, of seriousness and play.

Elusiveness unsettles planning, and it makes the performing of mobilities all but a given. Amongst others, factors such as (infra)structural possibilities and affordances, the proper carrying out of techniques of movement, and observance and understanding of rules, can affect individual performances. Emergent within spatial mobility performances, therefore, is elusiveness: a key property of any performance. No event can ever unfold the same way twice; no series of actionsno matter how routinized-can be reassembled in identical combinations. Differing situations, different relationships amongst actors, different permutations of action give rise to different potentialities and different actualizations, leaving a space and a time for something else, something unplanned or unexpected, to happen (Dewsbury et al, 2002). Elusive spatial mobilities can thus be understood as "creative relays... which may or may not find a hospitable destination" (Dewsbury et al, 2002, page 439).

\section{(Mis)Plays of the Day: A Random Collection}

June 30, 2007

Carly and her family have just missed a sailing to the mainland out of Langdale. Unbothered, instead of waiting for the next ferry at the terminal, they go back home to play chess and bake a pie. Good game, good pie... and bad timing, as baking and playing causes them to forget all about the clock. It's another mad rush to the ferry terminal. And another miss. But with two consecutive misses they are one short of tying Vince's record of three consecutive (sleep-induced) misses, set on Gabriola Island a couple of years before.

July 27, 2005 
Jay Leggatt misses the ferry from Tsawwassen to Mayne Island. Determined to make it there on time, he boards the ferry to Victoria, on Vancouver Island, farther west. En route to Victoria, while the boat crosses Active Pass near Mayne Island he leaps off the M/V Spirit of British Columbia aiming to swim the rest of the way to Mayne Island. He makes it ashore, but he is arrested by the police while on his way to the baseball game in which he was supposed to play. Banned for life by BC Ferries he has to leave the island and move to the mainland.

At night time, about twice a year, every year

Many islanders and coasters have difficulty sleeping the night before a morning departure. Others even have nightmares, like Ellen from Hornby Island: "I have this recurrent dream about twice a year. I miss the ferry, and then I have to walk this narrow, long plank to get on the boat. At times I dream of missing it and having to spend the night on Denman Island, or having to do these long, impossible leaps to catch the ferry, or even to have to swim to it, and then getting stranded out at sea."

Last week of August, every year

Bowen Islanders organize a unique road race on the island. The ferry's whistle works as the starting gun for a foot race whose aim is to make it back to the starting point before the departure of the next ferry, one hour later. Howe Sound is also the setting for another unique race, one that takes place year-round. For Texada Islanders, going to Vancouver and then coming home the same day is the name of the game. To win you need to leave Texada at with the 6:10am ferry. It is a 35 minute ride to Powell River. From there it takes 20 minutes to drive to Saltery Bay, which allows you to catch the 7:25 ferry to Earl's Cove. You ride the ferry for 50 minutes, then drive 90 minutes to Langdale. You get there by 10, in time for the 10:20 to West Vancouver. You reach downtown Vancouver before noon. You need to be back at Horseshoe Bay for the 5:30 back to Langdale. 
You're in Langdale at 6:10, and in Earls Cove in time for the 8:20. You get to Saltery Bay by 9:10

and then to Powell River at 9:30, in time to catch the last ferry to Texada, at 11.

Any day, any time

Ask Doby Dobrostanski how long it takes from the general store in Gillis Bay to the Texada Island ferry terminal at Blubber Bay, and through his song The Road to Blubber Bay, he'll tell you it can take 22 minutes, or a lifetime:

From the general store at old Gillies Bay

It's twenty-two minutes — or more I might say

If you drive a bit faster, it might be less,

'Cept if at the recycler you unload your mess.

And longer, I swear, sure it will take, If of lunch at the Tree Frog you do partake,

Slow down to salute our upholders of law, And stop at the thrift store to buy stuff for Ma!

If you drop off your sample for Doc Black at the clinic,

And chat with the staff ... don't be a cynic...

You can still make the ferry for the twelve-oh-five, But you'll have to get started on the winding long drive!

So on through the corners, past Leaper road, Swerve hard to miss vultures feasting on toad.

Slow at the Oasis, someone's riding a horse, And there's kids walking dogs_off leashes of course!

Stay on the road past the green veggie stand We there once got peaches - the ones that we canned.

At dusty Spragg road turn 'round the left curve, And right again, uphill, and don't lose your nerve!

Past the old house where the Stiles folks do stay, Give them a toot as you pass their drive-way!

Then cross the big meadow and Zaikow's old place, This stretch taunts one to make some more haste. 
And see the Log Inn-now sold it is said,

T'was a classy place once, with breakfast and bed.

The next of the drive is down to Priest Lake, Where frogs cross and die bravely, but why-for gosh sake?

Best get some fuel at our only gas station, Though prices are highest in the whole nation!

Gawk at the hotel; slow down at the hill, Turn left to Jane's bank and pay that old bill.

Then back to the car 'cause it's sure getting late With all these quick stops-but it's just our darn fate.

Right at the Esso, but gain speed with due care, Joggers n' pests (with antlers) congregate there!

Pass the police-house, and then do a right turn, Ah! Heischolt Lake; a swim does one yearn!

For just a half hour-so carry swim gear, So in case of onlookers you'll not have to fear.

And after a splash and a dive or two more, Turn back from the water and head for the shore.

Run to the car with hair sopping and wet, Jump in and start the trusty Chevette.

Down the long hill, past tall mountains of rock, When the light turns green, charge onto the dock.

You've made the whole trip to the Blubber Bay ferry,

A bit late, a bit wet, but it ain't all that hairy.

But next time, I think, you should take some more time, And help make this poem have verses that rhyme!!

Performances of mobility are not uniform, and like it is the case with all performances predictability is at times even undesirable. Making a scheduled departure, for instance, is not always "serious" business, but rather a practice characterized, at least at times, but the working out of a "mutant, undisciplined creativity" (Amin and Thrift, 2002, page 95). Life on small islands and remote coastal 
communities is marked by rhythms different from urban and suburban areas. For many islanders and coasters dwelling lifestyles are governed by distinct, reflexive temporal choices. Many people move to these communities, or choose to continue to live there, because of the putative freedom these places afford them in structuring daily routines. Self-employment, contract work, and retirement—some of the typical, albeit not exclusive forms of occupation—give many islanders and coasters flexibility in determining when and where to interact with the rhythms of the outside world. As Carly's nonchalant attitude toward catching a ferry and Doby's song highlight, the need to make a scheduled departure may then fall down in the scale of daily priorities for some, at least at times, well below the pleasures obtained from visiting with friends and neighbours, engaging in leisurely activities, and simply enjoying the ride. Hijacking words from McCormack (2002, page 483) in these cases making scheduled departures is a "way of moving that refrains from concluding with any certainty, but that from time to time and here and there creatively gestures and ventures from home."

Within circumstances such as these, it makes sense to think of mundane spatial mobilities as forms of play. Play is quintessential to performance, yet its relevance often goes undetected within the literature. Play is permissive, contradictory, light-hearted, loose, simultaneously directed at multiple purposes "forgiving in precisely those areas where ritual is enforcing, flexible where ritual is rigid" (Schechner, 2007, page 89). Play is flirtation with chanciness, the dance of control and release of one's hold over movement. Like Doby's improvised journey, playful mobilities are "doubleedged, ambiguous, moving in several directions simultaneously" (Schechner, 2007, page 89). Playful spatial mobilities subvert the seriousness of mundane travel, lighten the emotional load of responsibility, and deny the consequentiality of strategic planning. Rather than orchestrated, rational, strategic performances, playful mobilities tend to be spontaneous, moody, and relatively free. Even 
in those cases where mobilities are rule-bound, playfulness marks a performer's disengagement from mechanisms of social control.

Play, of course, is never free from social control as it is precisely within a relational engagement with mechanisms of control that the power of play is unleashed. Yet everyone, regardless of social position, can play. This is because in this context social markers such as class, or age, or ethnicity matter less than the forces of control exercised by the "outside world" — a distant, inimical social world which in one way or another seems to exert a uniform pull across individual lives. Whether one is commuting to dead-end job or high-professional workplace, trying to get to the supermarket, or meeting a friend on the other side in time, playfulness in this context is a disposition to living one's life along emergent paths, a freer "wayfaring" style of mobility that is keen on taking one's bee-line to the ferry terminal astray, as if for a walk (see Ingold, 2007). "To be an islander," in the words of an informant, "regardless of what you do for a living or where you've come from, means being able to say 'fuck it' any time of the day, and just play your game, your way."

Within the quotidian "there is always immanent potential for new possibilities of life" (Harrison, 2000, page 498). Basic rules both mitigate and allow for this potential. Catching scheduled departures is at times a relatively structured form of play. The structure of timetables allow for the possibility of an enjoyable challenge to movement. Catching a ferry is thus a form of play with regard to the elusiveness of its departure as an "eventuality" (Dewsbury et al, 2002, page 439) which informs how and why would-be passengers tackle the game. For example for Tom the function of play is to make it from Vancouver to Texada and back in one day, given the constraint and creativity the ferry schedule allows for. This is a form of agon, or competition, with winners and losers practicing skills and adjusting to challenging contingencies. Doby's light-hearted journey to Blubber Bay is more of a play of chance, a type of alea whereby making a scheduled departure is left to fate 
and casualness, a way of moving that is "not simply seduced by the attraction of speed, that is not afraid to stop, and perhaps to breathe" (McCormack, 2002, page 483).

Playful mobilities are also performances of mimicry in a way, a third common genre of play. Ellen's recurrent nightmare exemplifies this well. Ferries' scheduled departures are conditions that allow for ironic forms of play. This multidimensional form of play is an exercise in parodying the very dialectic of spatiotemporal freedom and dependency characterizing small island life. The more an islander or coaster separates oneself from the rhythms of the outside world, the more both the inside and the outside world become illusory, exaggerated caricatures of themselves. Playing cat and mouse with the ferry — in a way that is both serious and half-hearted — is a form of complicit makebelieve, a slaying of a self-created dragon, an exorcism of one's own ghosts. Edensor (2003) records similar patterns in dissecting drivers' commutes, arguing that the "everyday is not only that which embraces homogenous practices and experiences," because its "fantasies, stories, oddities, disruptions, lines of flights, and sensual intrusions complement habitual experience" (Edensor 2003, page 155). Elusiveness, in sum, brings creativity, undisciplined open-endedness, and ambiguity to the performance of mobility. Much like a cat-and-mouse form of play, the elusiveness of performance can make travel appealing, introducing elements of the unknown and even the undesirable.

\section{Ritualization}

6:45am: Monday, March 9, 2009.

BEEEP! BEEEP! BEE...click. The alarm is off. Time to get up. Sixty seconds for pants, socks, and a sweater. The bed stays undone; fixing it would waste ninety seconds. Time for a six-minute shower inclusive of tooth-brushing. No shampooing. If needed, shaving can be done on the ferry. Three minutes for the rest of the business. 6:55. Out of the bathroom. No breakfast. Dan grabs his backpack, walks downstairs, slips on lace-less shoes. The backpack contains breakfast, which can be consumed on the ferry. He takes 13 steps toward the car, switches the engine on. The car clock 
turns on. 6:57. He rolls out in forward drive, since he strategically backed in at night, and lights up a cigarette.

Dan is known for his scrambling to the ferry. But he is a strategic scrambler: he has everything planned. Merging onto the main road by 7:01am on a Monday is crucial, he says, as you need to get ahead of the school bus. The bus makes too many stops and you cannot pass it. Experience taught him: the school bus is headed to the ferry too and the ferry never leaves without the high school kids, but following it like a protective shield would not be a ticket to assured loading. The school bus has right of way: it skips the line-up and loads the ferry first. A driver following it would have to join the back of the line-up instead. That would not suffice on a Monday. Mondays are busy as many people leave the island for the whole week. So, this is not a day to show up at 7:19. You need to get there by 7:15. 7:10 if it was summer.

Careful planning is in order when you need to catch a limited capacity ferry. Many other islanders and coasters are strategic like Dan. For example, on Malcolm Island, residents of Mitchell Bay-over 25 minutes away from the ferry dock in Sointula-occasionally phone their friends in Sointula to ask them to go park their car in the line-up to hold a spot. When the friend arrives from Mitchell Bay at the last minute, the Sointula confederate moves the car out of the line-up and goes home. The void is immediately filled with the Mitchell Bay resident's car. It's crucial to hold that spot before the cut-off marker: road signs that indicate the exact point where the line-up has gotten too long. Some islands have no such signs, but everyone knows where the cut-off marker is: so-andso's house, somebody's driveway, or a particular tree. ${ }^{2}$

-- Insert Picture 1 about here --

Picture 1: The magic line on Bowen Island 
Traffic on these small islands is synchronized with the ferry timetable. Five minutes before a ferry is about to load, the rush minute begins. To cope with rush minute some islands have a ferry web cam installed near the line-up. As Dan explains, though:

They can be the worst example of group-think. People log on at, say, 6:50 and see no traffic, so they decide to wait before heading out. They do that again at 6:55. No traffic. So they don't leave yet. Then again at 7 o'clock, and maybe 7:05. No traffic. So they sit at home and wait. And then, wouldn't you know it, everybody is watching that web cam and doing the same thing, and they all leave at the same time. There are no cars lined up at 7:08 and next thing you know, one minute later, there are 40 cars arriving at once!

In the meantime Dan's car clock turns to $7: 14$. He is one turn away from the terminal. His right blinker goes forgotten as he makes the final turn. Then, the scene he will never forget unfolds before his eyes. The lot is deserted. No cars, no foot passengers, no crew. He gasps. His heart starts beating faster. His stomach begins to cramp. His skin pales. He slows down, he hesitates to proceed. One, two, three, four, five, six, seven, eight seconds of silence go by.

"What the hell?" he murmurs.

He drives up 50 meters. Every meter feels like a heavy step in an awkward walk of shame.

"Stephanie, what's going on?" he asks the ticket booth attendant.

"What do you mean, Dan?"

"Where's the 7:20?"

'It left on time exactly one hour ago, buddy. You haven't forgotten to adjust your clock for daylight saving time, have you?"

Performances of mundane spatial mobilities consist vastly of ritualized acts. Even when acts are seemingly spontaneous and improvised, the ways we move are a bricolage of re-arranged strategies 
and techniques in which we have moved before (see Bissell, 2009). People act on the basis of habits learned through previous observation, inquiry, imitation, and projected aims (Dewey, 1922; Ingold, 2000). Routine travel is clearly ritualized. When we engage in routine travel we enact patterns of movement shaped by prior experience, learned lessons, established conventions, and individual and collective memories which allow us to deal with the ambivalences and difficulties involved in the process of negotiating the timespaces of mobility. Like all rituals, daily mobile routines such as Dan's "tend to be stylized, repetitive, stereotyped [...and] to occur at special places and at times fixed by the clock, calendar, or specified circumstances" (Rappaport, 1979, page 175).

Rituals are marked by pre-liminal/liminoid, liminal/liminoid, and post-liminal/liminoid processes. In the context of an islander's or coaster's travel routine, making a scheduled departure is a pre-liminoid performance. Like other ritualized movements (see Ingold, 2000; Watts, 2008) preliminoid mobility rites of passage are skilful manifestations of efficient spatiotemporal craft. The essence of the pre-liminoid rite of gathering does not lie in its symbolic value as a form of transformation, therefore, but in its efficaciousness as a form of transportation. While they are both forms of craft, ritualized journeys like Dan's are just about the opposite of Doby's. Rather than funoriented, they are results-oriented; rather than focusing on the here and now they are focused on the there and then of mobility timescapes; rather than constantly self-aware of the flow of the experience, ritualistic performers like Dan are captive of their own habits and routine; rather than emphasizing the virtuosity of improvisation they emphasize the virtuosity of planning and structure; and rather than spontaneity they follow the ruse of tradition and well-rehearsed scripts. The preliminoid character of ritualized daily mobilities thus originates in the willingness to get beyond the threshold and on to the limen — in this case the point of boarding a ferry — and in the need to do so by achieving stability through repetition by way of actualizing "localised, context-specific knowledges about the hurdles involved in travelling" (Bissell, 2009, page 188). 
Pre-liminoid spatial mobilities are supposedly intended to annihilate the elusiveness of travel, but their success can never be guaranteed, as everyday life performances are marked by “multiplicity" (Dewsbury, 2000, pages 476-477) and "unexpectedness" (Taussig, 1992, page 41). Everyday life in general, after all, is "synonymous with the habitual, the ordinary, the mundane, yet it is also strangely elusive" (Felski, 1999, page 15). Repetition of individual action in timespace constitutes rhythms destined to exorcise the demon of scheduled departures, but "there is no identical absolute repetition" as "there is always something new and unforeseen that introduces itself into the repetitive: difference" (Lefebvre, 2008, page 6). But difference is not entirely undesirable, even to careful planners like Dan. There are good reasons for maintaining a window open to risk, unpredictability, and thrill. Showing up very early for a scheduled departure lacks affective appeal; it is too easy, predictable, boring, and repetitive. Timing one's arrival to the last minute is instead a way of displaying skill, embracing the affective value of difference and the pleasure of "action" in the sense intended by Goffman (1967). A scheduled departure after all is not an evil demon to stay away from, but a pixieish, devilish creature to flirt with. This way the ritual of gathering for a scheduled departure renews and re-energizes itself as a form of twice-behaved behaviour that is simultaneously never quite the same, but never too different from itself either.

Elusiveness is thus a struggle between the pre-liminoid and the post-liminoid phases of performance. The post-liminoid is the end of travel, its purpose. The pre-liminoid, instead, is a key moment of initiation. The post-liminoid calls for the pre-liminoid to unfold predictably, smoothly, according to plan. But the pre-liminoid moment occasions the confrontation of the resoluteness of purpose. In the pre-liminoid moment the actor must come to terms not only with his/her need to travel, but also his/her desire to do so. It is here that repetition undergoes scrutiny and difference exerts its seductive power. For Dan it's another minute in bed, the license of freedom of movement. For another less structured and regular commuter it could be the possibility of procrastination, or 
the negotiation of personal responsibility. Ritual structures and orders but does not annihilate innovation, and it is precisely within the pre-liminoid phase that mobilities open themselves up to the potential of the amiss, the awry, the astray, or in one word: the elusive.

\section{Drama}

"It's 5:15 already, we're not gonna make it!"

"We've got a chance. The car clock is seven minutes fast," Mike admonishes his incurably pessimistic wife. "You said that last time too," he adds.

"Yeah, but you almost got us killed last time, trying to beat that yellow light at Ladner Trunk road." “That stoplight is every islander's enemy. I give it the respect it deserves," Mike retorts.

Mike and Susan are barely out of the US-Canada border on Highway 99, with $25 \mathrm{kms}$ to get to the Tsawwassen ferry terminal, and a 5:45 sailing to Duke Point to catch. You can cover those $25 \mathrm{kms}$ in 17 minutes. But the problem is that it's a late spring Sunday. Even if they make the 5:35 boarding cut-off the ferry could be overloaded already.

“Honey, why don't we just drive to Horseshoe Bay and catch the 7 o'clock sailing?” Susan pleads.

"No way," Mike rebuffs her, "The hockey game is just about to get out. The traffic will be crazy. I don't want to show up at Horseshoe Bay late and have to wait for the 9."

"Mommy, daddy," little Tessa whines from the back seat, "can we stop to pee?"

“WHAT? Stop?! Are you crazy?!” both parents reply in unison.

Mike and Susan have been saying that to Tessa for the last hour. First the drive from the Bellingham airport, then the endless wait at the border. Now the mad rush. It's now 5:21 according to CBC Radio. Speaking of CBC Radio...

“Looks like it's a manic Sunday out there, eh Steve?"- the radio commentator announces. 
“Craig, it looks like the 6 o'clock from Tsawwassen to Swartz Bay is already full. There is still a lot of space on the 7 o'clock from Horseshoe Bay to Departure Bay, though the 5 o'clock did load up. In sports, the Canucks are now playing overtime..."

"Shit, wait, what about the Tsawwassen-Duke Point ferry?" Mike yells at the radio, "you NEVER tell us about the Duke Point ferry!!!” he screams.

"Mike, just go straight to Horseshoe Bay. If you turn for the Tsawwassen terminal now and we get there and it's too late, there is no way we can drive back onto the highway and make it to Horseshoe Bay on time."

Susan is right about that. If they get to Tsawwassen even as early as $5: 33$, but the ferry is overloaded and they don't want to wait there for the 8:15, it will take them at least eighty minutes to get to Horseshoe Bay, which will mean missing the 7 o'clock. Catching the 9 o'clock will get them on the island in Nanaimo at 10:35. Missing the 5:45 and catching the next ferry out of Tsawwassen will get them on the island, twenty minutes south of Nanaimo, at 10:15. Even by missing the 7 o'clock and catching the 9, they lose nothing. And at least they put themselves in a situation where their odds of catching the 7 o'clock (and being on the island at 8:35), are better than catching the 5:45 (and being on the island at 7:45, but still twenty minutes away from home. They do their statistics while driving $130 \mathrm{kmh}$.

“Ok, ok,” Mike surrenders.

"Good, then you can at least slow down to 120?" Susan mumbles out loud.

"Daddy, does that mean we can stop to pee now?"

"WHAT? Are you crazy," both parents reply.

The race is still on. 5:38: Massey Tunnel: cleared. 5:54: Oak Street bridge: cleared. 6:09: Left onto West King Edward Ave, traffic increases. 6:19: Granville Street bridge: cleared. Downtown traffic is clear, the Canucks are still in OT. 6:33: Lions Gate bridge: cleared. They have got a shot at 
this. "Shit, shit, why are we getting every red light in the world?" cries Mike, "COME ON!!!” He yells at an older driver ahead of him. Tessa is about to explode. 6:40: Upper Levels Highway: merge executed: $12 \mathrm{kms}, 8$ minutes, before the sailing cut-off. He's doing 130kmh again. 6:44. 6:45. 6:46: last exit is passed. Will the ferry be overloaded already? Will they enforce the loading 6:50 cut-off to the very second? Could the boat be late, even five minutes, the one time when you actually need it to be late? Why didn't they make reservations? Why is the US-Canada border such a jungle on Sundays? Can Tessa last ten more minutes? Is there a police speed trap behind that curve? Is that huge line-up ahead for the Sunshine Coast ferry or the Vancouver Island ferry?

6:49. "Two adults and a four year old to Nanaimo"- - he barks at the ticket booth attendant as he lurches out of his car window to pay.

“\$72.45 on your Mastercard,” she replies, as she glances at her monitor, “you’ve got a 50-50 chance of making it. The next one is at 9 o'clock."

The death knell of every islander's dream: the 50-50 odd.

"You gotta be kidding," cries Mike as joins the line-up,

"Honey, you know, we should have gone to Tsawwassen and caught the 7 to Swartz Bay. We'd have been on the island at 8:35 and in Nanaimo by 10," whimpers Susan, "just like I told you."

"Daddy, does this mean I can't go pee until tomorrow?"

The performance of movement is generated through linear trajectories, but also through re-routings, incidents, and swerves, as "the world does not resolve or come to rest" easily (Dewsbury et al, 2002, page 437). Indeed, not everything that emerges out of performance is intended or controlled (Schieffelin, 1998). Dramas epitomise this elusive quality. According to Turner (1974, page 37) social dramas are "units of aharmonic process arising in conflict situations." Viewing spatial mobilities as social dramas can allow us to understand routine travel's complex "topographies of apprehension" 
(Edensor, 2003, page 152) and magnify their elusiveness in a way no other concept can. Islanders and coasters thus experience the dramatic properties of elusiveness in conflicted ways. Elusiveness in this sense becomes a force to contend with: a rupturing affect marked by suspense. Elusiveness and suspense thus unfold simultaneously_-suspense is lived, effected, and practiced as a response to elusiveness.

Both elusiveness and suspense defy the linearity of movement. Their performance and experience is choreographed like an improvised dance of nervous gestures, of knee-jerks. Making a scheduled departure can be understood in part as a zigzag of adjustments to constantly mutating dramatic "convergences." Convergences are crossing points, bifurcations, irretrievable events, competing strategies and choices along the movement path. Convergences are doubt and conflictladen intersections and encounters that yield momentous outcomes for the rest of one's journey, outcomes that are "either connective (if...then), conjunctive (and...and), or disjunctive (either...or)" (Dewsbury, 2000, page 481). Depending on how converges unfold, dramas also unfold. Convergences, in other words, hold the potential for shaping and re-shaping the breaches, crises, redressive actions, and reintegrations and disintegrations that make up a drama.

Dewey's (1934) conceptualization of the experience of life rhythms is particularly useful for understanding the dramatic nature of spatial mobilities, and the experience and performances of convergences. According to Dewey life is built from tensions and releases of engagement with the world, as well as an affective, "aesthetic" disposition marked by vulnerability, need, and desire. Mike, Susan, and Tessa's travel experience can thus be understood as a rhythmic dance with possibilities, affordances, fate, and instrumentality marked by a process rich with affective significance. Four components of this process can be outlined and applied to our case: cumulation, conservation, tension, and anticipation (Dewey, 1934). These four dynamics nicely complement and overlap with 
Turner's social drama template, in that they underlie the very engagement of breaches, crises, and successive moves.

Cumulation is a form of affective build-up, arising from the progressive unfolding of travel within timespace. Ritual performances are frequently subject to cumulation in that their openendedness and fluidity foster a sense of becoming which is "constantly attaching, weaving and disconnecting; constantly mutating and creating" (Gardiner, 2000, page 502).Without speaking directly of cumulation, but still incidentally capturing its essence, Dewsbury (2000, page 480) writes: "every move you make is an untimely moment redistributing what has gone before while opening up what may yet come." The idea of cumulation applies well to Mike and Susan's handling of their journey's growing complexity, and the progressive deepening of the meaningfulness of catching their ferry. Their journey is not a linear, uniform one, but instead a "play of ducking and weaving and chasing through lines that always seem to be opening onto others" (McCormack, 2002, page 483), growing in intensity as they unfold. Cumulation is the key to affect. Without the cumulation arising from the handling of convergences and the ability to "offer quick responses to situations, responses which are able to intervene positively instead of simply going with the flow" (Thrift, 2003, page 2021) there can be no affect. Affect is thus in part generated by cycles of breach, crisis, and redressive action, as well as the growing anticipation toward a desired integrative outcome-such as the making of a scheduled departure.

Conservation is the process of holding onto the past affective forces of a journey; the forces implicated in the constant negotiation and re-assessment of a multitude of possible outcomes (cf. Dewsbury, 2000, page 475). Spatial mobilities are always practiced and experienced against a context of past affective economies in which energies of movement are cyclically released and expanded, and regularly reflected, re-engaged, and reassessed in "architectures of performative potential" (McCormack, 2005, page 122). For a local, travelling back home to Vancouver Island is not a 
spontaneous activity. Memories of countless journeys past inform your every turn, every sprint, every choice, “every turning you didn't take (but which still haunts you)" (Dewsbury et al, 2002, page 439). Mike and Susan know how long it takes to drive here and there, they know what their odds of making a scheduled departure are, and they know the risks of acceleration and deceleration from past experience. No mundane journey is an island unto itself; performers of spatial mobilities conserve past movements in all their instrumental and affective richness and draw upon them as they navigate their timespaces.

A third dimension is that of tension. Tension is a common, but neglected, feature of the quotidian. Everyday life is often thought of as trite, but it is instead a multidimensional, "fluid, ambivalent, and labile" (Gardiner, 2000, page 6) domain which is enriched by "transgressive, sensual, and incandescent qualities" (2000, page 208) full of tension. The practice of spatial mobilities can result in encountering (and creating) opposing tensions emergent in the "anxiety of completing the next task" (Dewsbury et al, 2002, page 439). These tensions work as resistances to free mobility, preventing immediate discharge and accumulat[ing] in intensity (Dewey, 1934, page 179). Tension is essential to drama because an utterly free performer, or conversely one without any agency, would experience no opposing energies, no resistance.

Finally, spatial mobilities are dramatic insofar as performers experience and practice affective regimes of anticipation. Anticipation hinges upon specific practices of temporality: individual actions and dispositions - more or less conflicted, intense, and consequential—-toward events such as scheduled departures which can stress and compress, extend and relax clock time. Like all forms of temporality (Adam, 2005; Watts and Urry, 2008), the temporality of scheduled departures is a performative affect emergent from located, ongoing practices of movement. Anticipation may occur before pre-liminoid acts, or throughout them. Planning a journey in advance exemplifies the former case, whereas hurriedly moving within a timespace in attempt to make a scheduled sailing epitomize 
the latter. Anticipation is thus the outcome of all affective dispositions towards the journey itself and the destination, and towards the scheduled departure as an immediate, irretrievable happening full of risk and chance (Dewsbury, 2000). Tension and anticipation are highest in two situations. The first is when islanders and coasters are departing for a journey that involves multiple connections. The second is when islanders and coasters are returning home from an out-of-the-usual trip. Other journeys tend to be marked by tension and anticipation less, yet without exception the timetable remains a "crucial actor" (Watts and Urry, 2008, page 868) in the performance of these less dramatic journeys as well. Cumulation, conservation, tension, anticipation are typical markers of all performances, and the performance of mobility cannot obviously escape their pulls and pushes. These dynamics unleash the dramatic affective power of spatial movement and produce conditions of suspense.

\section{The Suspenseful Elusiveness of Mobilities}

Throughout this paper I have shown how elusiveness marks (would-be) ferry passengers' orientation toward scheduled departures. A much understudied phenomenon in the mobilities literature, elusiveness is a central characteristic of all performances, and reflections on its relevance across contexts should prove to be fruitful for many mobilities researchers. Indeed as Goffman (1967, page 149) writes, "wheresoever action is found, chance-taking is sure to be." Making a scheduled departure is a form of chance-taking: the outcome of scheduled departures' "pulling" and individuals' "pushing" toward them. As pure, uncontrolled becoming, as a possibility constantly coming-to-be, elusiveness opens up interesting avenues for the non-representational researcher and theorist. While barely scratching the surface at best, in this paper I have argued that the elusiveness of mundane spatial mobilities is an emergent outcome of playful, ritualized, and dramatic performances. One can only think of some of the myriad situations in which mobilities become 
similarly elusive: from the way weather affects air and road travel, to how union strikes and airlines' economic instability can unsettle planned travel.

Elusive mobilities are exceptional, never quite complete, and always marked by "a dangerous supplement, a restless spirit" (Dewsbury et al, 2002, page 428) which constantly "pushes" (Thrift, 2008) social actors to the verge of tripping and falling. Trips and falls, metaphorically speaking, are indeed quite common experiences of movement, but their meaningfulness is highly variable. Various performative dynamics—-such as the ways in which different performances are ritualized, dramatized, or playfully enacted-shape the affective dimensions of mundane spatial mobilities. Amongst these dimensions there exist various degrees of excitation, tension, resistance, release, and economies of fulfilment, but also dread, boredom, and drudgery. Making a scheduled departure is always elusive, but not always so in exciting ways.

Whether they are something to write a song about or not, scheduled departures are always virtual and always haunted by the possibility of mishap and the emergence of unpredictability. These elusive possibilities do not always materialize but even when they do not journeys' complexity and indeterminacy escapes easy closure. Elusiveness, in other words, can never be annihilated. Scheduled departures' pull, therefore, always overspills onto landscapes of apprehensions: exacting capture, enlivening otherwise potentially empty, dreadful routines, animating multimodal movement across land and water. Scheduled departures are only seemingly fixed. Their eventfulness is certainly fixed and even irretrievable (provided a ferry actually leaves on time), but their pull exceeds the limits of fixity, affirming the gathering process as the fluid foreground of spatial mobilities, rather than the background. Within this foreground elusiveness produces an "affect [that] inhabits the passage" (Massumi, 2002, page 217) of social actors, an affect which ruptures and disturbs (Anderson, 2006) their routine rhythms as a melodic line of continuous variation (Deleuze, 1988). This affect is 
marked by suspense. While not always actualized, within a gathering the emergence of suspense is always virtual.

Suspense is synonymous with being suspended, with a liminal/liminoid condition of being in between, hanging, sensing contradictory feelings of pleasurable excitement and anxious anticipation. Suspense arises through the pull of the future, through the affect that the future calls forth and the elusiveness such call generates. "Without the force of the future"-writes Dewsbury (2000, page 480)_action is unimaginable" and yet, "despite expectations of what it is to come, this sense of future is likewise unforeseeable." Suspense is thus the product of unforeseeability combined with the human will to foresee. Suspense is the capacity to be affected by the future's indeterminacy, and the capacity to affect one's future. It is not easy to talk about suspense, to reflect upon it, to capture its fleeting characteristics. Yet suspense pervades our practice of everyday life, and-more to the point - the performance of spatial mobilities. Rather than by words, suspense is bespoken by the capacity for movement and for corrections to movements-gone-wrong, by the resilience of travellers attempting to capture their sailing of choice in spite of the indeterminacy of their journeys, and by the tension inherent in the chanciness of their performances.

Suspense highlights how making a scheduled departure is pure process, how it is about being neither here nor there, within "a space we might call the tension of the present tense" (Phelan, 1999, page 224). Suspense is a pure state of becoming emerging from a more or less disorderly succession of transitions, each "accompanied by a variation in capacity: a change in which powers to affect and be affected are addressable by a next event" (Massumi, 2002a, page 15). In sum, suspense is the product of elusiveness. Unwanted-because it is stressful — and yet sought-after because it affords excitement, novelty, and playfulness, suspense inspires a world of movement to keep on moving. In the words of Dewsbury and colleagues: "This is a world between potential and determination, between what has happened and what could, a world captured in the tension of its present tense of 
becoming, a not yet enacted moment where we meet and greet ourselves in the affect that inspires action" (Dewsbury et al, 2002, page 439). Difference and repetition, elusiveness and control, contingency and predictability_or in more simple words not making it or making it.

\section{Notes}

1. Due to limited space in this paper I can only focus on one dynamic of ferry-catching. Elsewhere I have discussed the intersection between ferry rhythms, speed, and duration and the temporalities of the island and coastal communities they serve, the performance of passengering aboard ferries, the temporal and spatial characteristic of waiting for departure in lineups, the narrative dimensions of recollecting and sharing notable trips, the taskscape of travel on island roads and marine routes, and the ritualization of ferry travel in general (Vannini, 2011b).

2. Such signs exert a suspenseful affective power of their own. As I explain in another article, ferry lineups are extremely uneven due to the presence of anomalous gaps between cars (Vannini, 2011b). These gaps vary in number and size, and no two lineups are ever alike. In practical terms this means that being in front of, or behind the "magic line" guarantees nothing. Thus, rather than settle the score and reduce the elusiveness of a sailing before a ferry departure, these signs often tend to add to the very drama of ferry-catching.

\section{Acknowledgment}

This research was made possible by a Standard Research Grant from the Social Sciences and Humanities Research Council of Canada. I would also like to thank April Vannini for her research assistance.

\section{References}

Adam B 2005 Time (Polity, New York) 
Amin A, Thrift N, 2002 Cities: Re-imagining the Urban (Polity Press, Cambridge)

Bissell D, 2009, “Conceptualising differently-mobile passengers: geographies of everyday encumbrance in the railway station” Social \& Cultural Geography 10173 - 195.

Binnie J, Edensor T, Holloway J, Millington S, and Young C, 2007, "Mundane mobilities, banal travels" Social \& Cultural Geography 8165 - 174.

Blumen O, 2007, “The performative landscape of going-to-work: on the edge of a Jewish ultraorthodox neighborhood" Environment and Planning D 25803 - 831.

de Certeau M 2002 The Practice of Everyday Life (UCP, Thousand Oaks)

Deleuze G 1988 Spinoza: Practical Philosophy (City Light Books, San Francisco)

Deleuze G and Parnet C 2006 Dialogues II (Continuum, London)

Dewey J 1922 Human Nature and Conduct (Holt, New York)

Dewey J 1934 [1980] Art as Experience (Perigee, New York)

Dewsbury JD, 2000, "Performativity and the event: enacting a philosophy of difference" Environment and Planning D 18473 - 496.

Dewsbury, JD Harrison, P Rose, M Wylie, J, 2002, “Introduction: enacting geographies” Geoforum 33 $437-440$.

Edensor T, 2003, "M6-junction 19-16: defamiliarizing the mundane roadscape" Space and Culture 6 $151-168$.

Felski R, 1999, “The invention of everyday life” New Formations 3915 - 31.

Gardiner M 2000 Critiques of Everyday Life (Routledge, London)

Goffman E 1967 Interaction Ritual (Pantheon, New York)

Grimes R 1995 Beginnings in Ritual Studies (USCP, Columbia)

Harrison P, 2000, "Making sense: embodiment and the sensibilities of the everyday" Environment and Planning D 18497 - 517. 
Holley D, Jain J and Lyons G, 2008, “Understanding business travel time and its place in the working day" Time \& Society 1727 - 46.

Ingold T 2000 The Perception of the Environment (Routledge, London)

Ingold T 2007 Lines: A Brief History (Routledge, London)

Jones P, 2005, "Performing the city: a body and a bicycle take on Birmingham, UK" Social \& Cultural Geography $6813-830$

Laurier E, 2004, "Doing office work on the motorway" Theory, Culture \& Society 4261 - 277.

Lefebvre H 2004 Rhythmanalysis (Continuum, London)

Lofgren O, 2008, "Motion and emotion: learning to be a railway traveller" Mobilities 3331 - 351.

Lorimer H, 2005, "Cultural geography: the busyness of being 'more-than-representational” Progress in Human Geography $2983-94$.

Massumi B 2002 Parables for the Virtual: Movement, Affect, and Sensation (Duke University Press, Durham, NC)

May J Thrift N, 2001, "Introduction" in Timespace: Geographies of Temporality Eds J May N Thrift (Routledge, London) pp 1 - 46

McCormack D, 2002, “A paper with an interest in rhythm” Geoforum 33469 - 485.

McCormack D, 2005, "Diagramming practice and performance” Environment and Planning D 23119 147.

Phelan P, 1999 “Andy Warhol: performances of 'Death in America”, in Performing the Body/Performing the Text Eds A Jones, A Stephenson (Routledge, London) pp 223 - 226

Rappaport R 1979 Ecology, Meaning, and Religion (NAB, Richmond, CA)

Schechner R 2003 Performance Theory (Routledge, New York)

Schechner R 2007 Performance Studies: An Introduction (Routledge, New York) 
Schieffelin E, 1985, "Performance and the cultural construction of reality" American Ethnologist 12 $707-724$.

Schieffelin E, 1998, "Problematizing performance", in Ritual, Performance, Media Ed. F HughesFreeland (Routledge, London) pp 194 - 207

Spinney J, 2006, "A place of sense: a kinaesthetic ethnography of cyclists on Mont Ventoux" Environment and Planning D 24709 - 732

Taussig M 1992 The Nervous System (Routledge, London)

Thrift N, 2003, “Performance and...” Environment and Planning A 352019 - 2024.

Thrift N 2008 Non-Representational Theory: Space, Politics, Affect (Routledge, London)

Turner V 1988 Dramas, Fields, and Metaphors (Cornell University Press, Ithaca NY)

Vannini P, 2011a, “The techne of making a ferry: a non-representation approach to passengers' gathering taskscapes" Journal of Transport Geography forthcoming.

Vannini P 2011b Ferry Tales: An Ethnography of Mobility, Place, and Technoculture on Canada's West Coast (Routledge, New York).

Watts L, 2008, “The art and craft of train travel” Social \& Cultural Geography 9711 - 726.

Watts L Urry J, 2008, "Moving methods, travelling times” Environment and Planning D 26860 - 874.

Wylie J, 2005, “A single day's walking: narrating self and landscape on the South West Coast path" Transactions of the Institute of British Geographers NS $30234-247$. 